\title{
DISPARITY OF MEDICAL CARE UTILIZATION AMONG DIFFERENT HEALTH INSURANCE SCHEMES IN TAIWAN
}

\author{
SHOU-HSIA CHENG* and TUNG-LIANG CHIANG \\ Graduate Institute of Public Health and Center for Health Policy Research, National Taiwan \\ University, College of Public Health, Taipei 10018, Taiwan
}

\begin{abstract}
Potential excess use of health care services caused by insurance has been a major concern for almost every industrialized county. Moral hazard problems and fee-for-service payment methods are considered to be important factors for higher medical care utilization among those insured. Health care availability is another feature reportedly associated with health care use. Using the data from a National Health Interview Survey in Taiwan in 1990, this study examined differences in medical care utilization by beneficiaries under three major social insurance plans (i.e. Labor Insurance-LI, Government Employees' Insurance-GEI, and Farmers' Insurance-FI) which covered about half the population at that time. Logistic and Poisson regression models were applied to examine the effects of relevant factors on the probability and volume of physician visits. Results from the analyses revealed that (1) persons with different insurance plans had a similar higher probability of seeing a doctor than the uninsured, with the odds ratios ranged from 1.8 to 2.0 . Also (2) the LI/FI participants consumed 60 $73 \%$ more physician services than the uninsured, while the GEI enrollees utilized only $30 \%$ more physician services. Findings from our study concerning the access and use of physician services in different insurance plans provide some useful information for reforming a health care delivery system. (C) 1998 Elsevier Science Ltd. All rights reserved
\end{abstract}

Key words - health insurance, physician services, availability of providers

\section{INTRODUCTION}

The theoretical base for the excess use of medical care services induced by health insurance is the socalled "moral hazard" problem. Basically, it is an extension of the Law of Demand - when price goes down, consumption goes up. When a person enrols in an insurance plan, the real price to him/ her for medical care services decreases (while the insurance premium becomes sunk cost to him/her), and the consumption may increase (Feldstein, 1988). The effects of insurance on health care utilization have been well investigated. The Rand Health Insurance Experiment, a remarkable study on this issue, reported that insurance has removed the financial barrier to health care, and increased the use of care in proportion to the level of free care (Manning et al., 1987). Many researchers made the same conclusion that insurance coverage increased the use of health care, including physician visits and admission to hospitals (Hillman et al., 1989; Davis, 1991; Trevino et al., 1991; Stearns et al., 1992; Hafner-Eaton, 1993; Hanh, 1994). People without health insurance have a higher denial rate in seeking health care (Saver and Peterfreund, 1993; Lieu et al., 1993).

Another theory for the increase in medical care use is the supplier-induced demand (or utilization). This hypothesis reveals that patients are relatively

*Author for correspondence. innocent due to the asymmetry of information. Physicians may induce the consumption of medical care for their own benefits instead of the patients' (Folland et al., 1993; Wennberg et al., 1982). Traditional fee-for-service plans provide incentives for physicians to provide more services to insurance enrollees. Capitation-based reimbursement methods had been introduced in response to the potential abuse caused by the fee-for-service based reimbursement. A recent review by Miller and Luft (1994) reports that HMO participants use more office visits and less hospital admissions, compared with those in fee-for-service plans. Hence, the medical care cost is lower for HMO enrollees than their fee-forservice counterparts. Shifting the financial risk from consumers to providers is the key feature. Removing the incentive of providing more (expensive) health care, i.e. supplier-induced demand, is the most significant factor for these findings.

Availability of health care providers is another issue in health care utilization. Rural residence and geographical availability of medical care has been reported to be associated with the use of health care services. It is generally concluded that urban area residents consume more services, and distance to a regular source of care is an important factor affecting the use of health care (Gesler and Meade, 1988; Cunningham and Cornelius, 1995; Love and Lindquist, 1995). However, lots of the geographical studies focused on the measurement issues of dis- 
tance-to-care rather than the availability of health care providers (Gesler, 1986). In Taiwan, health care services were provided to insurance beneficiaries through insurance-contracted providers, prior to the implementation of National Health Insurance (NHI) in March 1995. Different insurance plans had various contracted health care providers. The present study explored the insurance effect on the use of ambulatory care, within a unique situation where different types of insurance had a different level of availability of (contracted) health care providers. It is hypothesized that limited availability of providers may curb the insuranceinduced medical care utilization.

\section{HEALTH INSURANCE IN TAIWAN}

Taiwan is a small island of $36,000 \mathrm{~km}^{2}$, of which two-thirds is mountainous with few residences. In 1990, there were 21 million people, with about 19,900 western physicians (in addition to Chinese doctors) in 741 hospitals and 7221 clinics (Department of Health, 1994). All 365 townships, except five in remote mountain areas had at least one practicing physician. Most hospitals were closesystem based, i.e. physicians were hired as full-time employees in hospitals and were mainly paid salaries plus a performance bonus. Each of the hospitals had a substantial outpatient department. Clinic physicians were self-employed and totally independent from hospitals. Average household annual income was about 580,000 NT Dollars (Dept. of Budget, Account and Statistics, 1990) in Taiwan, with 1 U.S. dollar being equal to 27 NT dollars. The national health care expenditure was about $4 \%$ of the GDP. Generally speaking, in 1990 a person conducted 9 physician visits per year in Taiwan (Lin et al., 1991).

Three major types of social health insurance systems existed prior to the implementation of National Health Insurance plan on March 1, 1995. They were labor insurance (LI) which was mainly for private sector working employees, government employees' insurance (GEI), for all governmental employees and retirees, and farmers' insurance (FI) for all farmers. These three insurance types covered about one half of the total Taiwan population in 1990 (Lin et al., 1991; Department of Health, 1994). Children, students at school, housekeepers and the elderly were the main components of the uninsured population. Patient benefits of medical care services, including ambulatory care, hospital in-patient care and prescription drugs, were very similar under the three insurance plans. Instead of co-payment requirements, insurance beneficiaries had to pay a fixed "registration fee" (i.e. $50 \mathrm{NT}$ dollars) for each visit. Patients with no insurance coverage had to pay the full price (usually around NT\$ 300-400) out of pocket.
Premiums, payment method to providers, and medical care delivery for the Labor Insurance and Farmers' Insurance beneficiaries were basically similar. All administrative procedures for the FI were handled by the LI system. About $80 \%$ of hospitals and $47 \%$ of clinics were contracted with labor/ farmers' insurance. This figure accounted for $67 \%$ of all western physicians in Taiwan (Department of Health, 1994; Bureau of Labor Insurance, 1994). The LI/FI participants might receive physicians' services in these contracted hospitals' outpatient departments, or in contracted clinics. Contracted health care providers were reimbursed on a fee-forservice basis with the collected "insurance coupons" which were handed by the LI/FI patients, after receiving medical services.

On the other hand, government employees' insurance had its own health care delivery system. About $38 \%$ of all western physicians in Taiwan were contracted providers for the GEI enrollees. Sixty-one percent of the hospitals and less than $6 \%$ of clinics contracted with the GEI (Central Trust of China, 1994). The GEI also owned six clinical centers (the Government Employees Clinical Centers) in five metropolitan areas in Taiwan. Physicians from large hospitals were selected to provide scheduled primary care services in the six clinical centers. These doctors were paid fixed wages for each session in the clinical centers. Other physician services provided in contracted hospitals' OPDs or clinics were paid on a fee-for-service basis, similar to the LI/FI system. Approximately $40 \%$ of the primary care services were provided to the GEI enrollees by physicians in the six clinical centers in 1990 (Central Trust of China, 1994). A detailed description of Taiwan's health care system is available elsewhere (Peabody et al., 1995).

Major differences between the LI/FI plans and the GEI plan were: (1) the LI/FI system paid their contracted providers on a fee-for-service basis; the GEI system used a mixed payment method; (2) the availability of health care providers were different, with $67 \%$ vs $38 \%$ of all physicians contracted for these two systems respectively; (3) the GEI beneficiaries received primary ambulatory care only from physicians in the GEI clinical centers, or from contracted providers, before any referral could be made; this was not required for the LI/FI members. In consequence, in comparison to the LI/FI participants, seeking health care was less convenient and the freedom of choosing physicians was more limited for the GEI enrollees.

\section{MATERIAL AND METHODS}

\section{Data source and variables}

Data for this study came from a National Health Interview Survey in Taiwan. A total of 1193 households were selected, via stratified random sampling, 
as the target sample. Face-to-face interviews were conducted between May and August in 1990. A total of 1031 households with 4196 people of all ages were interviewed successfully, with a response rate of $86.4 \%$. This study sample was nationally representative (Lin et al., 1991). The majority of the failed cases were due to "moving out" and "wrong address"; the "refused to answer" cases accounted for $6.6 \%$ of the target sample. Of the interviewed subjects, 2664 adults aged 20 or over were included in the analysis, because most persons aged under 20 had no health insurance coverage in 1990.

Andersen's medical care utilization model was employed in the study (Aday and Andersen, 1974). Use of health care is affected by several factors such as individual demographic features, enabling factors, and need characteristics. Health insurance status was classified into four groups: labor insurance, government employees' insurance, farmers' insurance and the uninsured. Three dummy variables were created for the three insured status groups, while the uninsured was the reference. Dependent variables were the use of physician services (seeing a doctor or not), and the frequency of physician visits in the past two weeks. Visits to the emergency room in the hospitals was not included in the analysis. Ambulatory care referred to physician visits in clinics or outpatient departments in hospitals. Information on other correlated variables according to the Andersen model was also collected. Basic demographic characteristics included age, sex and education. Enabling factors included family income, family size, regular source of care, and urbanization of residence. Need indicators were represented by self-reported health status, and physician-diagnosed chronic conditions.

Measurement of the study variables is briefly described as follows. While using dummy variables in the analyses, we coded the event as 1 and the reference group as 0. Age was divided into three groups, and two dummy variables were used to represent the younger group of ages 20-44 and the middle age group of 45-64, while the older group was the reference. Education was represented by a dummy variable which was assigned 1 if a person attended high school or above, or else 0. A dummy variable was used to indicate a low income family, with less than 20,000 NT dollars (U.S. \$740) per month, which represented approximately the lower $20 \%$ of all families. Large family size was represented by a dummy variable, with family members equal to 4 or more. The definition of a rural area was modified from the Taiwan Standard Classification Report in 1990 (Directorate-General of Budget, Accounting and Statistics, 1993). A chronic condition was coded 1 , if an individual reported any of the following nine physician-diagnosed disorders: hypertension, heart diseases, stroke, diabetes, gastrointestinal ulcer, liver diseases, bronchitis, kidney disorders, and arthritis. Perceived health status was classified into three groups, i.e. good, fair, and poor health. Two dummy variables were created for the fair and the poor groups while the good health group was the reference.

\section{Statistical models}

An alternative statistic model was conducted to examine the effect of health insurance on the use of physician services. Frequently, multiple logistic regression is employed to investigate the probability of health care utilization. Although the odds ratio of seeking health care may be estimated, the disparity of the quantity of the utilization between groups could not be assessed. A traditional regression model is often conducted to estimate the increase of health care utilization caused by health insurance. Sometimes, a two-part model is used to deal with this situation. In this model, logistic regression is performed for all subjects first, then ordinary or weighted least square estimates are used for those who have had any physician visits (Kobashigawa and Berki, 1977; Manning et al., 1981; Nolan, 1993). It was noted that ambulatory care usage in a certain period of time should not be treated as continuous numbers; instead it would be more appropriate to be treated as counts. In our study, many subjects had no physician visits in the study period. Therefore, in addition to logistic regression, Poisson regression with a log link function was used in the study to estimate the effects of particular factors on the magnitude change of physician services utilization. Although a physician visit may not be independent from the previous visit by the same person, which does not fit the Poisson distribution, Cameron and Trivedi (1986) found that "the major impact of the distribution assumption is on estimated variances rather than point estimates of parameters".

An overdispersion problem was found in this study's Poisson regression model which indicated that the dispersion estimate was greater than 1 in the model. Using the SAS "genmod procedure", we specified the square root of model deviance divided by degree of freedom, as an estimate of the scale parameter (rather than the unity) in order to adjust the overdispersion (SAS Institute, 1993). This adjustment basically would not affect the model parameter estimate values, yet the covariance matrix would be enlarged. Hence the standard errors of the parameter estimates would be increased, which would make the parameter estimates less likely to be significant. Furthermore, we preferred to use $1 \%$ probability level as a cutoff point for defining statistical significance because of the large sample size.

While interpreting the results from logistic regression, we assumed that using physician services or not was mainly initiated by the patients rather than the physicians. Under this assumption, the problem of supplier-induced demand might be less 
severe. On the other hand, the number of visits (if greater than 1) in two weeks could be heavily influenced by the physician, e.g. repeated visits required by physicians. When the "number of physician visits" was treated as a dependent variable in the Poisson regression, the effects of independent variables might be contaminated by the influence of physicians - the health care providers. This idea should be born in mind.

\section{RESULTS}

\section{Description of sample characteristics}

The essential description of the sample is listed in Table 1. The male to female ratio was 1.0 for this sample. The mean age was about 42 years old. Forty percent of the subjects attended high school or above (greater than 9 years schooling). Among these adults, only $7 \%$ of them reported poor perceived health; $41 \%$ and $52 \%$ of the individuals reported good and fair health status, respectively. About $31 \%$ of the sample had physician-diagnosed chronic disorders. Twenty-one percent of the individuals came from low income families, and $71 \%$ of the subjects lived in large families. Sixty-four percent of the sample had a regular source of care. About $29 \%$ of the individuals lived in rural areas.

While comparing the basic distribution among individuals with the four types of insurance status, we noticed several obvious differences. First, farmers' insurance enrollees were the oldest group with a mean age of 56, while the labor insurance enrollees were the youngest, with a mean age of 38 . Second, the education level was extremely low for the FI enrollees with only $8 \%$ of the persons having attended high school or above. Third, the FI enrollees had the highest percentage $(15 \%)$ of perceived poor health and the highest percentage $(48 \%)$ with chronic conditions. Fourth, only $8 \%$ of the government employees insurance enrollees came from low income families, while $37 \%$ of the FI enrollees came from low income families. Finally and naturally, most of the FI enrollees $(69 \%)$ lived in rural areas. According to our knowledge, the uninsured group included house-keeping females, selfemployed businessmen, college students, unemployed persons, and the retired elderly. Health insurance status and these relevant factors were considered to be associated with the use of physician services.

\section{Physician services utilization}

Utilization of ambulatory care in the past two weeks in terms of the number of physician visits is presented in Table 2. The overall mean number of physician visits was 0.35 for the sample, with $82 \%$ of them not seeing a doctor at all in the two weeks prior to the interview. As expected, we found that insured people consume more physician services than the uninsured. Government employees had the highest percentage for seeing the doctor once $(12.7 \%)$, but FI enrollees had the highest percentage for seeing a doctor three times or more $(11.1 \%)$. The mean number of physician visits for the insured ranged from 0.33 to 0.60 ; it was only 0.26 for the uninsured. The differences in utilization among these four insurance groups were statistically significant at the $p<0.001$ level.

Females were more likely to see a doctor as well as to have more physician visits than males. A typical trend of utilization was observed among three age groups with means of $0.22,0.51$, and 0.70 , respectively, for the young, middle and old age groups. People with a higher education used less physician services than their counterparts. Need characteristics were found to be significantly associated with use of ambulatory care. Eighteen percent of those with a poor health status had visited their physicians three times or more in the last two weeks. On the contrary, only about $1 \%$ of those with good health used as many physician services. People with chronic conditions consumed three times as many physician services as those without chronic conditions ( 0.66 visits vs 0.21 visits). Those who had a regular source of care used more physician services than their counterparts. Family income and family size were not found to be significantly associated with ambulatory care utilization.

\section{Adjusted effects on physician services utilization}

Results from the logistic regression model for examining the insurance effects on the probability of seeing a doctor, and from the Poisson regression model for evaluating the effects on the quantity of

Table 1. Means for independent variables by types of insurance for adults over 20 in Taiwan

\begin{tabular}{|c|c|c|c|c|c|}
\hline Variables & Total $n=2664$ & $\begin{array}{l}\text { Gov. employee } \\
\quad n=252\end{array}$ & $\begin{array}{l}\text { Labor ins. } \\
n=1334\end{array}$ & $\begin{array}{c}\text { Farmers' ins. } \\
n=334\end{array}$ & Uninsured $n=744$ \\
\hline $\operatorname{Sex}(1=$ male $)$ & 0.50 & 0.46 & 0.50 & 0.52 & 0.49 \\
\hline Age (years) & 42.2 & 49.0 & 37.8 & 55.6 & 41.7 \\
\hline Education ( 1 = above high sch.) & 0.40 & 0.63 & 0.43 & 0.08 & 0.41 \\
\hline Perceived fair health & 0.52 & 0.51 & 0.51 & 0.57 & 0.52 \\
\hline Perceived poor health & 0.07 & 0.07 & 0.04 & 0.15 & 0.09 \\
\hline With chronic disease & 0.31 & 0.40 & 0.26 & 0.48 & 0.28 \\
\hline Low income family & 0.21 & 0.08 & 0.15 & 0.37 & 0.29 \\
\hline Large family size (over 4) & 0.71 & 0.65 & 0.75 & 0.65 & 0.69 \\
\hline Regular source of care & 0.64 & 0.73 & 0.64 & 0.53 & 0.66 \\
\hline Rural area & 0.29 & 0.16 & 0.24 & 0.69 & 0.23 \\
\hline
\end{tabular}


Table 2. Frequency distribution (\%) and mean numbers of physician visits by studying variables

\begin{tabular}{|c|c|c|c|c|c|c|c|}
\hline \multirow[b]{2}{*}{ Variables } & \multicolumn{7}{|c|}{ Number of visits in 2 weeks } \\
\hline & $n$ & 0 & 1 & 2 & $3+$ & mean & S.D. \\
\hline Total & \multicolumn{4}{|c|}{ Predisposing characteristics } & 4.5 & 0.35 & 0.90 \\
\hline \multicolumn{8}{|l|}{$\mathrm{Sex}^{* *}$} \\
\hline Male & 1334 & 84.7 & 6.6 & 4.8 & 3.9 & 0.30 & 0.86 \\
\hline Female & 1330 & 79.2 & 9.7 & 6.0 & 5.1 & 0.39 & 0.94 \\
\hline \multicolumn{8}{|l|}{ Age $(\text { years) })^{* * *}$} \\
\hline $20-44$ & 1689 & 87.1 & 6.8 & 3.9 & 2.2 & 0.22 & 0.68 \\
\hline $45-64$ & 677 & 75.2 & 10.2 & 7.2 & 7.4 & 0.51 & 1.09 \\
\hline $65+$ & 298 & 68.1 & 11.4 & 9.7 & 10.8 & 0.70 & 1.29 \\
\hline \multicolumn{8}{|l|}{ Education*** } \\
\hline Under high school & 1596 & 79.0 & 8.2 & 6.6 & 6.2 & 0.43 & 1.02 \\
\hline High school and above & 1068 & 86.4 & 8.1 & 3.6 & 1.9 & 0.22 & 0.67 \\
\hline \multicolumn{8}{|c|}{ Need characteristics } \\
\hline \multicolumn{8}{|l|}{ Perceived health*** } \\
\hline Good & 1082 & 93.3 & 3.4 & 2.2 & 1.1 & 0.11 & 0.48 \\
\hline Fair & 1389 & 77.3 & 10.6 & 6.8 & 5.3 & 0.43 & 0.98 \\
\hline Poor & 192 & 52.1 & 17.2 & 13.0 & 17.7 & 1.07 & 1.49 \\
\hline \multicolumn{8}{|l|}{ Chronic condition $* * *$} \\
\hline With & 822 & 68.1 & 12.3 & 10.3 & 9.3 & 0.66 & 1.21 \\
\hline \multirow[t]{2}{*}{ Without } & 1842 & 88.2 & 6.3 & 3.2 & 2.3 & 0.21 & 0.68 \\
\hline & \multicolumn{7}{|c|}{ Enabling characteristics } \\
\hline \multicolumn{8}{|l|}{ Health insurance*** } \\
\hline Gover. employee & 252 & 77.0 & 12.7 & 8.3 & 2.0 & 0.36 & 0.75 \\
\hline Labor insurance & 1334 & 82.3 & 8.1 & 5.5 & 4.1 & 0.33 & 0.87 \\
\hline Farmers' insurance & 334 & 73.9 & 8.1 & 6.9 & 11.1 & 0.60 & 1.24 \\
\hline Uninsured & 744 & 86.7 & 6.7 & 3.5 & 3.1 & 0.26 & 0.81 \\
\hline \multicolumn{8}{|l|}{$\begin{array}{l}\text { Family income } \\
\text { (NT\$1000) }\end{array}$} \\
\hline Less than 20 & 565 & 80.7 & 7.8 & 5.3 & 6.2 & 0.40 & 0.99 \\
\hline 20 and over & 2099 & 82.3 & 8.3 & 5.4 & 4.0 & 0.33 & 0.88 \\
\hline \multicolumn{8}{|l|}{ Family size (persons) } \\
\hline 3 or less & 763 & 81.5 & 8.8 & 5.4 & 4.3 & 0.36 & 0.96 \\
\hline 4 or more & 1901 & 82.2 & 7.9 & 5.4 & 4.5 & 0.34 & 0.88 \\
\hline \multicolumn{8}{|l|}{ Regular source of care* } \\
\hline With & 1699 & 80.4 & 9.2 & 5.9 & 4.5 & 0.37 & 0.92 \\
\hline Without & 952 & 84.8 & 6.2 & 4.6 & 4.4 & 0.31 & 0.88 \\
\hline \multicolumn{8}{|l|}{ Urban/Rural } \\
\hline Urban & 1892 & 81.3 & 9.1 & 5.6 & 4.0 & 0.34 & 0.87 \\
\hline Rural & 759 & 83.6 & 5.7 & 4.9 & 5.8 & 0.36 & 0.97 \\
\hline
\end{tabular}

$* p<0.05$.

$* * p<0.01$.

$* * * p<0.001$ based on $\chi^{2}$ test.

physician services, are presented in Table 3 . We found that after controlling other factors in the model, the two need factors (perceived health and having chronic disorders), two predisposing factors (age and sex), and three enabling factors (insurance, regular source of care, and urban/rural area) were associated with the likelihood of seeing a doctor. Most of these factors were also observed to be correlated with the quantity of use of physician services.

The effect of health insurance on the probability of visiting a physician was obvious, with parameters estimated around 0.61 to 0.69 , and $p<0.001$. The odds ratios of seeing a doctor for the three types of insured individuals (LI, GEI, or FI) to the uninsured were close to each other, at around 1.8 to 2.0. However, the effects on the quantity of physician visits used by enrollees, for the three types of insurance, were different. Farmers' insurance enrollees consumed $73 \%$ more physician services than the uninsured (beta $=0.55$, the odds $=1.73$ since the $\log$ link function was used). Labor Insurance participants used $60 \%$ more services (beta $=0.47$, the odds $=1.60$ ) than the uninsured. Both FI and LI effects were statistically significant at the $p<0.001$ level. Conversely, the GEI beneficiaries utilized only $30 \%$ more physician services (beta $=0.26$, the odds $=1.30$ ), than the uninsured and the effect was not statistically significant.

Both needs indicators, perceived health and chronic conditions, had the most obvious effects on physician services utilization in the models. Results from the logistic regression showed that the odds ratio of seeing a doctor was 3.1 (beta $=1.12$ ) for the fair health group and 7.1 (beta $=1.96$ ) for the poor health group to the good health group, with $p<0.001$. Results from the Poisson regression revealed that after controlling demographic and enabling factors in the model, the needs characteristics had very significant influence on the quantity of ambulatory care use. The poor health group utilized about 5.1 times the physician services, and the fair health group consumed about 2.9 times more physician services, than the good health individuals. This finding highlighted the fact that health need was a critical determinant of the use of physician services, which is common sense and should not be ignored. Results for most of the other controlling 
Table 3. Results of ambulatory care utilization from logistic and Poisson regression models

\begin{tabular}{|c|c|c|c|c|}
\hline \multirow[b]{2}{*}{ Variables } & \multicolumn{2}{|c|}{ Any physician visit } & \multicolumn{2}{|c|}{ No. of physician visits } \\
\hline & beta & S.E. & beta & S.E. \\
\hline Sex $=$ male & -0.29 & $0.11 * *$ & -0.15 & $0.07 *$ \\
\hline Age $=45-64$ & 0.42 & $0.14^{* *}$ & 0.41 & $0.09 * * *$ \\
\hline Age $=65+$ & 0.59 & $0.19 * *$ & 0.57 & $0.12 * * *$ \\
\hline Education $=$ above high school & 0.016 & 0.14 & -0.09 & 0.09 \\
\hline Perceived health $=$ fair & 1.12 & $0.15^{* * *}$ & 1.06 & $0.11 * * *$ \\
\hline Perceived health $=$ poor & 1.96 & $0.21 * * *$ & 1.63 & $0.14 * * *$ \\
\hline Having chronic condition & 0.62 & $0.12 * * *$ & 0.53 & $0.08 * * *$ \\
\hline Insured - gov. employee & 0.64 & $0.21 * *$ & 0.26 & $0.14^{\wedge}$ \\
\hline Insured - labor insurance & 0.61 & $0.15^{* * *}$ & 0.47 & $0.10 * * *$ \\
\hline Insured - farmers' insurance & 0.69 & $0.19 * * *$ & 0.55 & $0.11 * * *$ \\
\hline Low family income & 0.01 & 0.14 & -0.04 & 0.09 \\
\hline Family size $=4$ or more & 0.13 & 0.13 & 0.08 & 0.08 \\
\hline Regular source of care & 0.31 & $0.12 * *$ & 0.18 & $0.08 *$ \\
\hline Rural area & -0.36 & $0.14 * *$ & -0.15 & $0.09^{\wedge}$ \\
\hline Intercept & -3.75 & $0.25 * * *$ & -2.96 & $0.17 * * *$ \\
\hline Log likelihood $\chi^{2}$ & \multirow{2}{*}{\multicolumn{2}{|c|}{$322.22 / \mathrm{DF}=14$}} & & \\
\hline Deviance/DF & & & \multicolumn{2}{|c|}{1.087} \\
\hline
\end{tabular}

Omitted group is aged 20-44, with good perceived health, and uninsured.

$\hat{p} p<0.10$.

$* p<0.05$.

** $p<0.01$.

$* * * p<0.001$

variables, such as age, sex, regular source of care, and urbanization, were similar to those reported in previous studies (Lin et al., 1991; Trevino et al., 1991; Lieu et al., 1993; Hanh, 1994).

\section{DISCUSSION}

Consistent with the findings of previous studies, this study demonstrates that health insurance increases the probability, as well as the quantity, of physician visits. The three health insurance plans (LI, GEI, FI) had a similar effect on the likelihood of seeing a doctor. After controlling other factors in the models, we found that the odds ratio of visiting a doctor was about 1.8 to 2.0 for the insured to the uninsured. As we mentioned earlier, "seeing a doctor or not" was mainly decided by the consumer rather than the provider. The findings revealed that no difference in the likelihood of physician visit was observed among beneficiaries under the three insurance schemes.

On the other hand, the number of physician visits utilized by the LI/FI enrollees was higher than that of the GEI participants. The LI/FI beneficiaries consumed $60-73 \%$ more ambulatory care than the uninsured. Yet, the GEI members utilized only $30 \%$ more services. We wondered why the GEI enrollees did not "use up" the physician services as did other insured persons. What were the possible explanations? Major factors concerning differences among the beneficiaries' characteristics such as age, perceived health, and chronic diseases were included in the model, with significant effects on the amount of physician visits. Three alternative explanations were considered: level of convenience (availability of providers), financial incentives of providers due to payment methods, and quality of care.
Since limited freedom of choice and referral are prevalent in many countries (OECD, 1994), disparity of the availability of health care provision was the first reason we thought of. The contracted health care providers for the GEI were very limited. Only $38 \%$ of all physicians in the Taiwan area were their contracted providers and many of the physicians were working in hospitals. On the contrary, $67 \%$ of physicians were contracted with the LI/FI system. In addition, there was a referral requirement for GEI beneficiaries to obtain more advanced examination or treatment. Limited availability of health care providers (which implies some spatial inconvenience and less freedom in provider selection) could partially account for fewer physician visits by GEI members than LI/FI enrollees.

Financial incentives for medical care providers could be another influencing factor. We noted earlier that the LI/FI contracted health providers collected "insurance coupons" and were reimbursed on a fee-for-service basis. This payment method provided incentives for physicians to see more patients, or to see a patient many times, in order to collect more coupons. Conversely, the GEI contracted physicians who saw patients in the six GEI clinical centers were paid fixed wages. This payment method might limit or prevent unnecessarily repeated visits to physicians in the six GEI clinical centers.

The third alternative explanation is that quality of care to the GEI beneficiaries could be better than that to other programs' participants. Most of the GEI contracted providers were large (teaching) hospitals with good reputations. Although we had no indicators on quality of medical care, we did have a variable from the survey on overall satisfaction with medical care services. We found no differences in levels of satisfaction with medical care 
services between GEI and LI/FI beneficiaries with $43.2 \%$ satisfied, $50.8 \%$ fairly satisfied, and $6.0 \%$ dissatisfied among the former and $41.1 \%$ satisfied, $53.7 \%$ fairly satisfied, and $5.2 \%$ dissatisfied among the later two.

Family income was reported to be an important factor associated with health care utilization (Hafner-Eaton, 1993; Saver and Peterfreund, 1993; Freeman, 1993; Cunningham and Cornelius, 1995). Yet low income was not found to be significant in our physician services regression model, which is worth explanation. In 1990, the average charge for physician services was about 300-400 NT dollars or about 11-15 U.S. dollars per visit, which was relatively inexpensive compared to the monthly income of 740 U.S. dollars for lower income families in Taiwan. The affordable cost could be the most important reason for this finding concerning the family income effect. Rural residence was not expected to be a significant factor influencing the use of physician services, because Taiwan is a small island with a crowded population. Generally speaking, except for the remote mountain areas or offshore islets, it was not too inconvenient for consumers to access their doctors. However, we still found that people living in rural areas were less likely to see a doctor.

The problem of "moral hazard" indicated by the excess use of medical care by insured persons is always hard to identify, since it is difficult to know what amount of services is appropriate for a patient under certain situations. Results from this study revealed that even with the inexpensive cost of physician services, differences of medical care utilization existed between the insured and uninsured. Limiting the availability of health care provision, accompanied by mixed payment to physicians (i.e. fee-for-service and fixed wages), may alleviate the higher utilization among the insured population, as the case of GEI illustrates. In a low-income country with relatively insufficient medical care resources and little public or private insurance, limiting the availability of physicians may result in declining the utilization of medical care services. Nevertheless, while health care cost-containment is one major task for every industrialized country and many middle-income developing countries which are expanding insurance coverage, results from our study concerning the access and use of physician services in different insurance plans, provide useful information for reforming a health care delivery system.

Acknowledgements - This study is supported in part by grants from the Department of Health (DOH84-HR-305) and from the National Science Council (NSC85-2417H002-018) in Taiwan. The authors owe thanks to Drs F. C. Hu and C. H. Hsiao for their advice on the use of Poisson regression model. The reviewer's helpful comments are also appreciated.

\section{REFERENCES}

Aday, L. A. and Andersen, R. M. (1974) A framework for the study of access to medical care. Health Serv. Res. 9, 208.

Bureau of Labor Insurance for Taiwan-Fukien Area (1994). Statistical Data for Taiwan-Fukien Area Labor Insurance, p. 372. Taipei, Republic of China.

Cameron, A. C. and Trivedi, P. K. (1986) Econometric models based on count data: Comparisons and applications of some estimators and tests. J. Applied Econometrics 1, 29.

Central Trust of China (1994). Statistical Data for Government Employees' Insurance, p. 474. Taipei, Central Trust of China, Republic of China.

Cunningham, P. J. and Cornelius, L. J. (1995) Access to ambulatory care for American Indians and Alaska natives; the relative importance of personal and community resources. Soc. Sci. Med. 40, 393.

Davis, K. (1991) Inequality and access to health care. Milbank $Q$. 69, 253.

Department of Budget, Account and Statistics (1990). Report on the Survey of Family Income and Expenditure Taiwan Province, p. 20. Taichung, Department of Budget, Account and Statistics, Taiwan Provincial Government, Republic of China.

Department of Health (1994). Health and Vital Statistics: General Health Statistics, p. 126. Taipei, Department of Health, Executive Yuan, Republic of China.

Directorate-General of Budget, Accounting and Statistics (1993). Standard Classification for Statistical Areas. Taipei, Directorate-General of Budget, Accounting and Statistics, Executive Yuan, Republic of China.

Feldstein, P. (1988). Health Care Economics, 3rd edn. John Wiley and Sons Inc., New York.

Folland, S., Goodman, A. C. and Stano, M. (1993). The Economics of Health and Health Care, p. 204. Macmillan Publishing Co., New York.

Freeman, H. E. (1993) Insurance status and access to health services among poor persons. Health Serv. Res. 28, 531.

Gesler, W. M. (1986) The use of spatial analysis in medical geography: A review. Soc. Sci. Med. 23, 963.

Gesler, W. M. and Meade, M. S. (1988) Locational and population factors in health care-seeking behavior in Savannah, Georgia. Health Serv. Res. 23, 443.

Hafner-Eaton, C. (1993) Physician utilization disparities between the uninsured and insured. Comparison of the chronically ill, acutely ill, and well nonelderly populations. JAMA 269, 787.

Hanh, B. (1994) Health care utilization: The effect of extending insurance to adults on Medicaid or uninsured. Med. Care 32, 227.

Hillman, A. L., Pauly, M. V. and Kerstein, J. J. (1989) How do financial incentives affect physicians' clinical decisions and the financial performance of health maintenance organization? N. Engl. J. Med. 321, 86.

Kobashigawa, B. and Berki, S. E. (1977) Alternative regression approaches to the analysis of medical care survey data. Med. Care 15, 396.

Lieu, T. A., Newacheck, P. W. and McManus, M. A. (1993) Race, ethnicity, and access to ambulatory care among U.S. adolescents. Am. J. Public Health 83, 960.

Lin, R. S., Chiang, T. L., Hong, Y. T. and Chang, M. C. (1991). The Planning and Experience of the National Health Survey 1990. Final Report to the DOH, Executive Yuen, Taipei.

Love, D. and Lindquist, P. (1995) The geographical accessibility of hospitals to the aged: A geographic information systems analysis within Illinois. Health Serv. Res. 29, 629.

Manning, W. G., Morris, C. N., Newhouse, J. P., et al. (1981) A two-part model of the demand for medical 
care: preliminary results from the Health Insurance Study. In Health, Economics, and Health Economics, eds. J. van der Gaag, M. Perlman. North-Holland, Amsterdam.

Manning, W. G., Newhouse, J. P., Duan, N., Keeler, E. B., Leibowitz, A. and Marquis, M. S. (1987) Health insurance and the demand for medical care: Evidence from a random experiment. Am. Econ. Rev. 77, 251.

Miller, R. H. and Luft, H. S. (1994) Managed care plan performance since 1980. A literature analysis. JAMA 271, 1512.

Nolan, B. (1993) Economic incentives, health status and health services utilization. J. Health Econ. 12, 151.

OECD (1994). The Reform of Health Care System: A Review of Seventeen OECD Countries. OECD, Paris.

Peabody, J. W., Yu, J. C.-I., Wang, Y.-R. and Bickel, S. R. (1995) Health system reform in the Republic of China: Formulating policy in a market-based health system. JAMA 273, 777.
SAS Institute (1993). SAS Technical Report P-243. SAS STAT Software: The GENMOD procedure, p. 20, 32. SAS Institute, Inc., Cary, NC.

Saver, B. G. and Peterfreund, N. (1993) Insurance, income, and access to ambulatory care in King County, Washington. Am. J. Public Health 83, 1583.

Stearns, S. C., Wolfe, B. L. and Kindig, D. A. (1992) Physician responses to fee-for-service and capitation payment. Inquiry 29, 416.

Trevino, F. M., Moyer, M. E., Valdez, R. B. and StroupBenham, C. A. (1991) Health insurance coverage and utilization of health services by Mexican Americans, Mainland Puerto Ricans, and Cuban Americans. JAMA 265, 233.

Wennberg, J. E., Barnes, B. A. and Zubkoff, M. (1982) Professional uncertainty and the problem of supplierinduced demand. Soc. Sci. Med. 16, 811. 